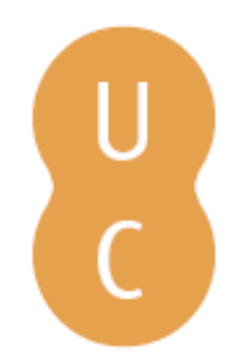

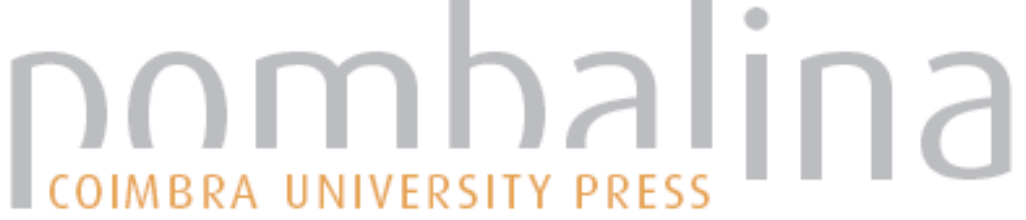

\section{Pretendidos derechos humanos que no son tales}

Autor(es): Quintana Cabanas, José María

Publicado por: Imprensa da Universidade de Coimbra

URL

persistente: URI:http://hdl.handle.net/10316.2/32418

DOI: $\quad$ DOI:http://dx.doi.org/10.14195/978-989-26-0767-2_4

Accessed : $\quad$ 26-Apr-2023 11:46:20

A navegação consulta e descarregamento dos títulos inseridos nas Bibliotecas Digitais UC Digitalis, UC Pombalina e UC Impactum, pressupõem a aceitação plena e sem reservas dos Termos e Condições de Uso destas Bibliotecas Digitais, disponíveis em https://digitalis.uc.pt/pt-pt/termos.

Conforme exposto nos referidos Termos e Condições de Uso, o descarregamento de títulos de acesso restrito requer uma licença válida de autorização devendo o utilizador aceder ao(s) documento(s) a partir de um endereço de IP da instituição detentora da supramencionada licença.

Ao utilizador é apenas permitido o descarregamento para uso pessoal, pelo que o emprego do(s) título(s) descarregado(s) para outro fim, designadamente comercial, carece de autorização do respetivo autor ou editor da obra.

Na medida em que todas as obras da UC Digitalis se encontram protegidas pelo Código do Direito de Autor e Direitos Conexos e demais legislação aplicável, toda a cópia, parcial ou total, deste documento, nos casos em que é legalmente admitida, deverá conter ou fazer-se acompanhar por este aviso.

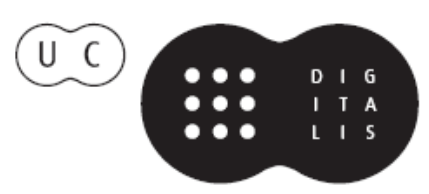




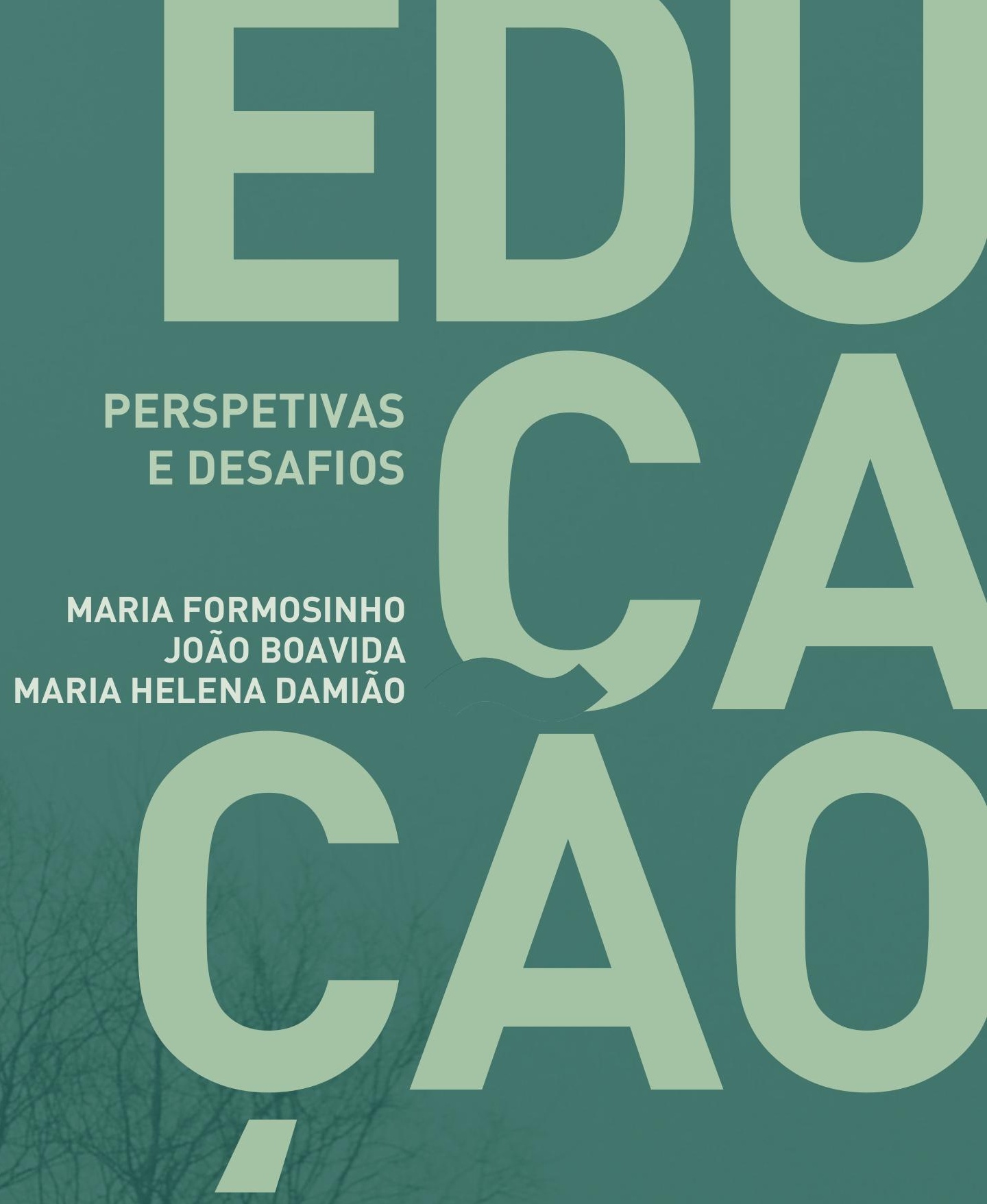

IMPRENSA DA

UNIVERSIDADE

DE COIMBRA

COIMBRA

UNIVERSITY

PRESS 


\section{José María Quintana Cabanas}

Universidade Nacional de Ensino a Distância (Madrid)

\section{PRETENDIDOS DERECHOS HUMANOS \\ QUE NO SON TALES}

\section{Introdución}

Los derechos humanos, aunque sean propios de la humanidad, han debido ser proclamados, conquistados y defendidos. Pero antes han tenido que ser descubiertos. Y, por cierto, esto ha costado tiempo y esfuerzo: hasta la época de la Ilustración no se ha hablado de ellos. El motivo es que, en medio de tanta opresión histórica de todo tipo, cuesta hacerse una idea de la libertad y del derecho.

Pero ocurre, además, que la definición de un derecho humano puede ser difícil y oscura desde el punto de vista teórico. Sucede en esto igual que en las cuestiones de Moral: los grandes principios son evidentes, pero ciertas cuestiones de detalle, aunque derivadas de aquellos principios e incluidas en ellos, puede ser muy difícil establecer esta relación y llegar a precisar su signo y el carácter de la obligación moral que encierran. Lo mismo ocurre en derechos humanos: algunos de ellos se intuyen fácilmente, mientras que otros requieren reflexión y demostración. No es extraño, pues, que en este camino la mente pueda ofuscarse y extraviarse, llegando a conclusiones incorrectas y viendo como derechos cosas que no lo son, o no viendo claramente si lo son.

Es de algunas cuestiones de esas que deseamos ocuparnos aquí. No de un modo profundo y exhaustivo, sino meramente aproximativo. Lo único que pretendemos es llamar la atención sobre la complejidad teórica de las cuestiones morales humanas, suscitar la cautela sobre el juicio que nos formemos acerca de algunas de ellas y dar pistas para 
reflexionar sobre ciertos derechos humanos de un modo más cuidadoso y exacto de como muchos lo hacen. Nuestra opinión personal no quiere aquí dar soluciones, sino más bien animar y aproximar a un estudio crítico de los temas.

\section{Sobre la noción de derecho}

El primer problema que se nos ofrece es ya la propia noción de derecho humano, o - si se quiere, y antes aún - la misma noción de derecho. Pues no todos la entienden de la misma manera. La principal divergencia está en la relación de derecho con el bien moral debido, pues opinan unos que esta relación es real y necesaria, mientras que para otros no lo es.

Sucede en esto igual que con el concepto de ley, con el cual el de derecho es correlativo. También para algunos la ley debe servir al cumplimiento de preceptos morales, mientras que para otros no tiene, en sí, ninguna relación con ellos (cf. J.M. ${ }^{a}$ Quintana 1995, pp. 225-231). Los primeros profesan la teoría racionalista del derecho, afirmando que la obligación jurídica emana con necesidad de las normas éticas conocidas racionalmente. Los otros se atienen a teorías positivistas del derecho, según las cuales la obligación jurídica emana de tipos de coacción provocada por ciertas instancias fácticas y empíricas, sobre todo de tipo social. La teoría de los primeros se llama del "iusnaturalismo", por entender que la base de toda ley positiva ha de ser la ley natural. Los positivistas jurídicos existen precisamente porque no creen en la ley natural: al ser ésta conocida por la razón, todas las filosofías (y han sido varias en la época moderna) que niegan la capacidad cognoscitiva de la razón humana han de ser de signo positivista.

Esto explica, por ejemplo, el caso de Kant, que es uno de los que separan la moral y el derecho y, por consiguiente, a remolque de su formalismo moral (según el cual no puede determinarse el contenido preceptual de los actos morales) proclama también el formalismo jurídico. Según éste el derecho no tiene que ver con los actos "justos", sino sólo con el ámbito de la libertad humana: todo lo libre es jurídico, es derecho. 
Contra lo cual argumenta A. Bonilla y San Martín (1897) que la libertad es condición y requisito indispensable para la existencia del derecho, pero no es el derecho mismo, porque éste tiene una referencia esencial a la realización del bien, al cumplimiento del deber, a la ejecución de actos «justos». Según dicho autor el derecho no se define por la libertad, pues ambos conceptos no son equivalentes; el hombre - dice - tiene libertad para obrar mal, pero cuando obra mal no ejercita un derecho; éste, en efecto, nunca servirá para el mal, pues el derecho no es aquella libertad que se ejecuta cuando se obra mal.

Como vemos, Bonilla y San Martín es iusnaturalista en su concepción del derecho. Pero antes de seguirle en la misma, recordemos que durante el siglo $\mathrm{xx}$ ha habido tendencia a separar derecho y moral, por influjo de corrientes llamadas de la Ciencia del Derecho; esa concepción puramente normativista del Derecho alcanzó su más exacta formulación en 1962 por obra de H. Kelsen, considerado como el mayor jurista del siglo xx. Pero a causa de una corriente del humanismo moderno vuelve ahora la tendencia a relacionarse derecho con moral; se trata de un iusnaturalismo renovado, o neo-iusnaturalismo, que se refiere a la ética dialógica de J. Habermas y K.O. Apel.

Comencemos siguiendo a Bonilla y San Martín en la distinción que, en su libro Concepto y teoría del derecho (1897), hace entre un concepto vulgar y un concepto racional de derecho. Dice (p. 45ss) que en su concepción vulgar siempre se emplea la palabra derecho en el orden legal indicando una facultad inherente al sujeto, propia de la personalidad humana, y siempre relacionada con algo que en sí es bueno y justo, con lo cual cabe decir que "el derecho es una facultad moral de obrar" (p. 47). En cambio, en su concepto racional "derecho es la facultad de obrar lo justo, y pues que la noción de lo justo implica relación de igualdad y de conformidad con la Ley, podríamos afirmar asimismo: derecho es la facultad de obrar en conformidad con la Ley" (p. 69s).

Entiende, pues, nuestro autor que el derecho va unido a la ley, y la ley va unida a lo justo. Se trata del concepto moral de derecho, visto éste como la "facultad de realizar lo justo, de acuerdo con lo que el deber exige, con lo que la ley prescribe y respondiendo a la existencia del Deber 
mismo" (p. 78), hasta el punto de que podría decirse que "el Derecho es la Voluntad conforme a la razón" (p. 79) e incluso, si se quiere, "el Derecho es la Moral en acción" (p. 126).

Esta concepción, formulada hace ya cien años, vuelve a encontrar eco -como decíamos- en tratadistas actuales. Pues, según se afirma en M. Canto-Sperber (1996, p. 447), "la genealogía de la idea moderna de unos derechos y libertades muestra una necesidad de fundar esas dos formas de la existencia moral y jurídica en el concepto de una identidad humana descubierta en la naturaleza y mostrada y luego afirmada por la razón".

El derecho humano es algo muy genérico. Pero cuando se habla de "derechos humanos", en plural, parecen estos referirse a la situación de las personas en el seno de la comunidad, más bien que a la posición de un derecho universal construido en referencia a la idea de autonomía de una persona. Los derechos humanos, en plural, se refieren a la protección, en los Estados de derecho, de que el hombre privado goza en su seguridad personal frente a las arbitrariedades del poder público, basándose en la idea de que "las personas tienen derechos morales contra el Estado”, según la expresión de R. Dworkin.

\section{El derecho de equivocarse}

Y pasando ahora a analizar lo que cabe pensar de ciertos pretendidos derechos humanos, comencemos por uno de ellos: el tan invocado derecho de equivocarse. Respecto del cual vamos a adoptar una actitud de crítica y repulsa, pues, a nuestro entender - y tal será nuestra tesisla posibilidad que tiene uno de equivocarse no es un derecho, sino una desgracia.

Lo que ocurre es que la posibilidad humana de equivocarse es tan general como frecuente: según decían los antiguos, humanum est errare. Es un hecho en el cual caen incluso los más inteligentes y avispados, aun sin culpa. Esto hace que normalmente no podamos culpar a nadie de haberse equivocado. Por otro lado a menudo los errores se refieren a decisiones personales cuyo verdadero resultado se percibe sólo después 
de la experiencia, con lo cual uno no admite tesis ni advertencias con anterioridad a la misma. Por todo ello parece que exponerse a equivocaciones es algo normal y natural, por no decir el método de llegar a conocimeintos y certezas. Esto es precisamente lo que se está pensando cuando se invoca el derecho a equivocarse; sin pensar que, en el campo del aprendizaje humano, hay algo mejor y más apropiado y aconsejable.

Justamente defendemos nosotros la conveniencia de aprender de la enseñanza de los expertos y por la buena reflexión personal. Por la educación, en definitiva, que se muestra más ventajosa, rápida y efectiva que por el aprendizaje "por ensayo y error", el cual utiliza las equivocaciones personales.

El ensayo y error constituye realmente un método de aprendizaje, pero, a nuestro entender, no el mejor ni el más rápido ni aconsejable. Es el método de quienes no disponen de otro mejor. Pero la educación e instrucción sistemáticas lo superan con creces.

Por cierto que, a nivel epistemológico, hay quien ha defendido el método de aprender de los errores como siendo el que de veras hace avanzar los conocimientos humanos. Nos referimos a K. R. Popper y su teoría de la falsabilidad, según la cual la ciencia avanza, más que adquiriendo nuevas verdades, demostrando el error de las que hasta ahora se tenían por tales; y así dice (1967, p. 281) que "toda refutación debe ser considerada como un gran éxito; no solamente del científico que refutó la teoría, sino también del científico que creó la teoría refutada y, así, sugirió en primera instancia, aunque sólo fuera indirectamente, el experimento refutador". Para este autor (según dice en otro libro, 1986) los enunciados que no cumplen la condición de falsabilidad no llegan a poder establecer la diferencia entre dos enunciados cualesquiera dentro de la totalidad de los posibles enunciados básicos "empíricos"; pero notemos que puede haberlos también de otro tipo, a saber, los "racionales", y en estos la certeza puede ser a priori, de modo que en ellos la falsación no constituye un método esencial, sino sólo accidental, ocasional.

Admitimos que también por descubrimiento de los errores avanzamos, pero es éste un modo de avanzar sólo indirecto y lento. Cuando advertimos la equivocación lo adecuado será aprovechar para huir de ella; ahora 
bien, el mejor acercamiento a la verdad, el de más calidad cognitiva, es el que se hace de un modo directo y progresivo.

Nuestra idea es que el error es esencialmente negativo, es un mal en sí, es un disvalor y algo, por consiguiente, que débese evitar a toda costa. Ya Tomás de Aquino enseña que el entendimiento humano, de por sí, es órgano de la verdad, y cuando cae en error es sólo por defecto. En su objeto propio (a saber, la esencia de las cosas, los primeros principios del conocimiento) "el entendimiento nunca se engaña", "el entendimiento es verdadero en su operación” (Summa Th., 1 q. 85 a. 3; 1959, p. 437), aun cuando puede errar al juzgar de las cosas en su complejidad y en las relaciones de sus diversos accidentes. Todo conocimiento auténtico es verdadero; un conocimiento erróneo no es conocimiento, sino mera ilusión cognoscitiva.

Según Descartes todas las ideas que son "claras y distintas" son de por sí evidentes y, eo ipso, ciertas y verdaderas. En su libro Reglas para la dirección de la mente (1983, p. 146, regla II) afirma que "toda ciencia es un conocimiento cierto y evidente", de modo que las dudas no hacen a un hombre más sabio. "Y por ello - llega a decir Descartes - vale más no estudiar nunca que dedicarse a temas hasta tal punto difíciles que, al no ser posible distinguir lo verdadero de lo falso, se vea uno forzado a admitir como cierto lo que es dudoso, pues en tal caso no hay tanta esperanza de aumentar la instrucción de uno cuanto peligro de disminuirla". Para este autor el método de la mente ha de ser avanzar de una certeza a otra y, "en la búsqueda del camino recto de la verdad, no debe uno ocuparse de ningún tema sobre el cual no pueda tener una certeza tan grande como la de las demostraciones de la aritmética y la geometría" (p. 151).

Igualmente para Spinoza lo verdadero tiene en sí mismo su propia señal: cuando una idea es adecuada es también verdadera. De todo eso se sigue que la equivocación no forma parte, de por sí, del avance de los conocimientos humanos. Cuando está, es sólo por accidente, por un fallo humano. Pero no debería estar; los conocimientos pueden avanzar con errores: pero no por los errores, sino a pesar de los errores. $\mathrm{Y}$ al no ser algo positivo, el error no puede constituir objeto de un derecho humano, el cual (según hemos visto antes) es de signo positivo. Un derecho, por consiguiente, 
puede y debe defenderse; y está claro que la equivocación no es algo que requiera o merezca una defensa. Uno no puede equivocarse cuando bien le parezca; sino que, a ser posible, uno no debería errar nunca. Pasa en esto igual que, por ejemplo, en los accidentes: si uno tiene un accidente de trabajo o de circulación puede que, en determinadas circunstancias, no lo culpemos por ello; pero no se le ocurrirá nunca defenderse diciendo que "tenía derecho al accidente". El error no merece disculpa ni tolerancia; las merece la persona, que, en sus limitaciones, yerra.

El derecho de equivocarse ha sido defendido por la escuela moral de los utilitaristas (seguidores de Stuart Mill), si bien el derecho al error no lo han justificado en sí mismo, sino sólo (siguiendo la línea teórica y argumentativa de esa escuela) por la utilidad que tienen los errores, ya que provocan una discusión que engendra la verdad; de suerte que, si se tolera el error, es porque - dicen - puede dar lugar al nacimiento de la verdad.

Ya hemos dicho nosotros que el error puede, efectivamente, tener este resultado; pero eso sólo de un modo indirecto y extrínseco, lo cual no justifica el admitir el error como el camino ordinario e indispensable hacia la verdad.

En este asunto nosotros preferimos - igual que hemos hecho antes - atenernos a la doctrina de Bonilla y San Martín, el cual en su mencionado libro la formula de un modo tan apropiado como convincente. Comienza por decir que el carácter distintivo del derecho es la bondad: "la condición de bondad manifiéstanos desde luego que la libertad de pensamiento es un derecho cuando se ejercita bien, y no lo es cuando se practica mal. El hombre está obligado a pensar bien, y aun cuando no siempre sabe cuándo piensa mal, una vez averiguado, carece de derecho para continuar pensando de aquella manera; de suerte que la libertad de pensamiento no puede ser nunca un derecho absoluto, sino un derecho sub conditione. Lo mismo puede decirse del error si averiguamos que estamos en él, porque corre parejas con el pensar mal" (p. 124s).

La idea de este autor se basa en lo que ya hemos dicho: el error es un mal, y un mal nunca puede ser objeto de derecho. Su fórmula es la siguiente: "el derecho no puede nunca servir para el mal, luego si el error es mal no existe derecho al error" (p. 129). En definitiva: "El hombre 
tiene derecho a manifestar su opinión cuando ésta es verdadera, pero no cuando es errónea, a sabiendas de su naturaleza; y como la verdad sólo estará probada para el hombre cuando se haya discutido, la precitada manifestación es condición indispensable para la aparición de la verdad y debe existir". En este asunto la misión que incumbe al Estado, que ha de proteger la libertad y el bien, es que debe permitir y tolerar la libertad de discusión como algo inexcusable que necesariamente se ha de consentir.

\section{El derecho de huelga de quienes trabajan en servicios públicos}

El derecho de huelga es una fuerza que permite la resistencia de los débiles contra abusos a que los someten los fuertes. En este sentido loado sea ese derecho, pero mientras se ejerza dentro de los límites insoslayables de la justicia.

En nuestra era industrial la huelga se ha descubierto como un medio de combatir la injusticia social en el ambiente empresarial. $Y$ ha sido tal su éxito y su eficacia que ha venido a mitificarse como medio de reivindicación, pasándose a emplearlo en situaciones en que no resulta apropiado. Es esta extrapolación la que quisiéramos aquí denunciar y discuttir.

La huelga constituye un medio de violencia y de fuerza. Cosa que resulta oportuna cuando se trata de resistir precisamente a una situación injusta impuesta por la violencia y la fuerza. En este sentido la huelga es una verdadera guerra. Tanto lo es, que la moral relativa a la huelga es (para la Teología Moral, por ejemplo) exactamente la misma que la moral relativa a la guerra, entendiendo que la guerra, para respetar la moral (cf. R. Jolivet 1959, pp. 425ss), ha de tener una causa justa y no han de existir posibles soluciones pacíficas, y ha de ejercer sólo una violencia proporcionada, "que prohíbe cualquier violencia que vaya más allá de lo necesario para defenderse u obtener la reparación del derecho" (p. 426).

Ahora bien, una guerra sólo se justifica cuando se dirige contra quien causa una exacción, un perjuicio injusto, precisamente para eliminarlos. 
Una guerra sin alguna eficacia posible no tendría justificación ni sentido. Pues bien, eso mismo es lo que ocurre con la huelga.

Está claro su papel en el caso de la huelga en el trabajo industrial. Si el patrono somete a los obreros a condiciones injustas de trabajo, y estos se niegan a trabajar, su actitud causa un perjuicio al patrono, el cual, por simple egoísmo interesado, deberá hacer concesiones a los obreros. La huelga, pues, en este caso es plenamente eficaz.

Esta eficacia ha llevado a plantear la huelga como forma de reivindicación en todos los conflictos laborales. Pero no todos responden al modelo industrial, con lo cual la huelga no tiene en ellos el mismo sentido ni los mismos efectos que en este caso, de modo que posiblemente no sea justa como lo es en el modelo industrial.

Esto puede y debe decirse, especialmente, en el caso de los funcionarios y otros profesionales empleados en servicios públicos (Administración, transportes, sanidad, bomberos, etc.). Si hacen huelga, a menudo no están perjudicando directamente a sus empresarios respectivos (el Estado, el Ayuntamiento, etc.), sino sólo indirectamente, y el perjuicio directo es para unos terceros (los usuarios) que no tienen poder de decisión en la solución del conflicto ni son causa del mismo. Esto es simplemente una injusticia. Como decía en cierta ocasión un comentarista, en ese caso los huelguistas tienen tomados a los usuarios "como rehenes». Por eso M. Vidal (1991, p. 729) dice que la moral cristiana pide mayor circunspección en relación con determinadas huelgas, a saber, las que hemos indicado; pero no llega a decir que sean ilícitas.

Nosotros (cf. J. M. ${ }^{a}$ Quintana 1989, p. 442s) hemos discutido este tema a propósito de las huelgas de los enseñantes, y afirmábamos que la huelga es un instrumento de reivindicación legítimo sólo en las corporaciones laborales (industriales, etc.) que no desempeñan profesiones liberales ni de servicios públicos, de modo que queda fuera de los derechos de los docentes si estos pretenden que su profesión es de tipo liberal.

Siendo la huelga una medida perturbadora, es lícita únicamente en última instancia y en cuanto que es contundente, es decir, que constriñe al empresario a conceder lo que debía y no quería. Ahora bien, este resultado, que es seguro en el campo empresarial, no tiene ninguna garantía de 
éxito en el campo de la Administración o servicios, por cuanto los perjudicados no son los dueños o directivos de los mismos, sino unos terceros. El trasladar el recurso de la huelga a esos campos es inapropiado. Estamos de acuerdo en que, también en ellos, si se producen abusos e injusticia con respecto a los empleados, estos tienen pleno derecho a ejercer la oportuna reivindicación. Pero ésta no debe ser la huelga, sino otros medios. El recurrir a la huelga se hace por falta de imaginación, pues, en vez de pensar en los recursos apropiados (influjo en la opinión pública, publicidad de las reivindicaciones, etc.), lo único que se hace es extrapolar un recurso que es propio de otro campo, y lo que es derecho de unos y en unas circunstancias se proclama derecho de todos y en cualquier circunstancia.

En el caso concreto de los enseñantes advertía ya P.W. Musgrave que la huelga es poco profesional, porque causa un mal a los alumnos. Con esto no puede ser un derecho de los docentes, ya que el estatuto de estos les impone el deber de buscar el bien de sus alumnos.

\section{La desobediencia civil y la objeción de conciencia}

La sociedad democrática ha llevado a la institución de un Estado de derecho, que se distingue porque en él todos los individuos son iguales ante la ley, y porque es ésta, y no el poder de algunos individuos, lo que regula los derechos y las obligciones de todos ellos.

A partir de aquí, pues, los individuos, conociendo sus derechos personales, pueden hacerlos valer, reivindicándolos frente a las pretensiones del Estado o de los poderes constituidos, cuando exigen algo que conculca aquellos.

Ahora bien, esto tiene un peligro. Y es que, a fuer de hablar de derechos, algunos individuos se obsesionan con ellos $\mathrm{y}$, olvidando por otra parte sus deberes - que también los tienen -, reivindican ciertos derechos que no son tales o que hay que juzgar como excesivos, ilegítimos. Hay casos que, por ser oscuros y difíciles, se prestan a discusión, siendo esto lo que ocurre en cuestiones tales como la desobediencia civil y la objeción de conciencia. Vamos a hacer algunas reflexiones sobre ellas. 
Si admitimos la moral como principio regulativo de la ley, resulta que una ley inmoral no obliga. Esta puede ser la base teórica que justificaría la desobediencia civil. El problema es el de quién decide si una ley es inmoral, dado que la autoridad social parece más competente, para decidir en esto, que el simple individuo. Por eso puede éste ponerse en problemas con la autoridad constituida cuando pretende, contra el criterio de ésta, practicar la desobediencia civil.

La desobediencia civil sólo se tolera y se justifica (según autores como Rawls, Dowrkin o Habermas) "dentro del sistema democrático”, es decir, cuando no se considera desobediencia a la Ley, sino sólo a normas legales concretas, en cuanto que se discute la funcionalidad de éstas para lograr el bien común, que es lo que teóricamente pretenden. Se tolera la desobediencia civil de los ciudadanos en tanto que estos, con tal actitud, pretenden algo mejor - según ellos - para la sociedad. Sólo así se justifica su actitud.

La desobediencia civil, dice J. Sádaba, tiene que ver con la debatida cuestión de la conciencia como último tribunal para decidir, propiamente, una acción; en el sentido de que la licitud de ésta depende de lo que dicta la propia conciencia. Pero hay que ver la concepción que se tenga de la misma; por ejemplo, puede parecer muy discutible la siguiente definición que J. Sádaba (1997) da de conciencia: "la conciencia no es sino el saber sobre nosotros mismos, la capacidad para conocer como nadie cuál es nuestro grado de asentimiento a lo que hacemos; la imposibilidad, en fin, de autoengañarnos" (p. 156). Semejante subjetivismo parece muy poco adecuado a la objetividad que ha de ser propia de la ley y la moralidad.

Según la explicación de J. Rawls (1995, p. 413), la desobediencia civil es un acto político emprendido por un individuo contra una disposición legal que él considera injusta y fuente de injusticias; de tal modo que la oposición a la misma se hace apelando al sentido de justicia de la comunidad, entendiendo que éste debe estar, por derecho, por encima de la ley. "Al participar en la desobediencia civil, tratamos de dirigirnos al sentido de la justicia que tiene la mayoría, y a dar a conocer que, según la propia opinión, sincera y meditada, las condiciones para la libre cooperación están siendo violadas” (p. 424). 
En conclusión, cabe decir que la desobediencia civil es un auténtico derecho del individuo, pero siempre que él esté razonablemente seguro de que esa desobediencia constituye un acto moral y socialmente mejor que la obediencia que se le exige. Y ahí está el problema, porque puede equivocarse, en cuyo caso no le asiste derecho objetivo alguno sino que, además, se hace reo de desobediencia a la ley, con todas sus consecuencias pertinentes.

Desde el punto de vista de la Filosofía Política, la llamada objeción de conciencia constituye un caso de desobediencia civil y, por consiguiente, vale para ella todo lo que ya llevamos dicho. Pero al ser un caso especial, cabe añadir todavía algunas consideraciones más.

Esa también llamada insumisión a hacer el servicio militar puede tener grados: pues una cosa es negarse a la práctica de lo militar, remplazándola por una "prestación social sustitutoria", y otra cosa la llamada "insumisión total", por considerar que todo lo militar está vinculado de base a una "violencia antipacifista", que se rechazaría radicalmente y por principio. Quienes adoptan tal actitud suelen basarse en unos motivos que así viene a resumir J. Sádaba (1997, p. 154): el servicio militar "refuerza poderes inertes y acríticos de lo militar, estimula el patriotismo acrítico, imposibilita una formación para la paz y recorta las posibilidades de una juventud claramente formada en la misión de un mundo distinto al de las fronteras y sus consecuentes defensas armadas".

Como se ve, los insumisos dicen serlo, y quieren justificar su posición, en nombre de una concepción pacifista de la vida, que les parece ser la verdadera y la única admisible.

De la buena voluntad e intención de los insumisos nadie duda. Pero de lo que puede dudarse es que sus teorías tanto antropológicas como sociales sean verdaderas y acertadas, a partir de lo cual la insumisión puede ser discutida. Y no sólo discutida, sino incluso ser tenida por antisocial, en cuyo caso su posible insolidaridad no podría ser consentida, sino que incluso debería ser combatida y penada.

Dentro de la problemática que ahí se suscita, apuntemos únicamente alguna reflexión, que puede llevar hacia alguna solución. Solución que habría de ser realista. 
Nos parece, en efecto, que la teoría de la insumisión, igual que el pacifismo a ultranza, pecan de utópicos, porque se basan en la idea de unos seres humanos sin egoísmo ni agresividad, cosa que viene a discordar de lo que la experiencia nos muestra todos los días. Y si hay personas, grupos humanos y naciones agresivos, opresores y expoliadores, es obvio que a los atacados les asiste no sólo el derecho, sino también el deber de resistir. Aun condenando, pues, toda guerra opresiva, parece cosa ingenua y perjudicial el condenar también la guerra defensiva. Es muy triste tener que admitirlo y confesarlo, pero parece acertado aquel dicho de los antiguos: si vis pacem para bellum. A partir de aquí cobra fuerza la idea de que tanto la defensa nacional como el procurar la seguridad pública y el goce de los derechos de los individuos constituyen un deber social, al que están moralmente obligados los individuos si su colaboración se hace indispensable para la consecución de aquellos bienes sociales. Si esto es así la insumisión ha de ser vista como simple insolidaridad social y desobediencia a una ley justa. Si la conciencia de tal o cual persona lo ve de otro modo esto es irrelevante, pues ya sabemos que hay conciencias "erróneas", y que el subjetivismo no es principio de un buen orden social (cf. J. M. ${ }^{a}$ Quintana 1984, p.186s).

\section{5. "Mi cuerpo es mío y de él puedo hacer lo que quiera»}

Vamos ahora a referirnos a una serie de pretendidos derechos que tienen un denominador común, a saber, su referencia al propio cuerpo, de un modo u otro, aunque con implicaciones y supuestos diversos. Son especialmente delicados en el sentido de que se refieren a unos valores humanos radicales, que afectan a la propia vida, la cual es un valor humano fundamental, casi un fin en sí, por encima de muchos otros valores, que son simples medios para la vida humana.

También desde el punto de vista moral esos derechos tocan puntos graves y fundamentales. Por eso a menudo se ha puesto pasión tanto en la defensa como en la impugnación de esos derechos, que aparecen como pretendidos por unos y discutidos o negados por otros. Su formulación 
es reciente, y se refieren a varios aspectos, algunos de los cuales vamos a comentar a continuación.

La moral y el Derecho tradicionales son restrictivos con esos supuestos derechos, porque contradirían puntos básicos de la moral y el derecho, según el punto de vista generalmente adoptado. En cambio, la modernidad, con su pensamiento permisivo e individualista, ha adoptado un cirterio progresista, reconocedor de esos derechos. El criterio de esta última posición viene a inspirarse en este principio que así enunciaba A. Bertrand en 1874: "Cada uno tiene derecho de hacer el mal que sólo a él perjudica, el mal que no lesiona la libertad de otra persona" (en Bonilla y San Martín 1897, p. 121).

Una concepción moralista choca con este principio, que rompe con la objetividad de lo moral, es decir, con el concepto de lo que es malo en sí. Para este principio no hay cosas malas en sí, sino que es malo sólo aquello que, en unas circunstancias dadas, tiene consecuencias malas. Es el "consecuencialismo" como teoría moral. También deriva de la concepción puramente "formal" que Kant tiene del derecho, el cual consistiría en la simple libertad; en este sentido cuando uno actúa con libertad actúa ya, por ello, moralmente bien. También se justifica el mencionado principio desde la óptica actual de una teoría moral dialógica y democrática: si las normas morales son meras convenciones de no lesionar los derechos de los demás, resulta que no es inmoral el lesionar los propios derechos. Podría serlo el lesionar los propios deberes, pero en una moral dialógica no hay más deberes que los deberes sociales. Y esto abre la puerta a unos pretendidos derechos que nunca había reconocido la moral tradicional. Veamos algunos.

\section{El derecho a la conducta homosexual}

De la homosexualidad hoy día se habla mucho pero se escribe poco. Y, sobre todo, no se escribe en un plan científico y fundamentado que permita resolver los muchos problemas inherentes a ese tema. Precisamente nosotros hemos querido hacer aportaciones en este sentido, dedicando a 
varios puntos de esa cuestión el último capítulo de nuestro libro Pedagogía Axiológica. La educación ante los valores (1998). Uno de esos puntos, muy oscuro y debatido, es el origen de la homosexualidad, y otro es el de la valoración que de la misma hay que hacer, tanto a título individual como social, y de lo cual derivan normas de moralidad pública y de educación, de orientación y de valoración para todos.

En la explicación genética de la homosexualidad nos basamos en la teoría biológica de G. Marañón, según la cual aquella viene a ser un estado intersexual debido a una anomalía en el desarrollo de la persona. Esto hace que la homosexualidad sea congénita y una característica personal propia de algunos individuos. Pero solamente de aquellos que así han nacido, y que serían muy pocos, porque, frente a esa homosexualidad "natural", la de la mayoría de quienes se dicen homosexuales sería puramente "circunstancial", es decir, debida a circunstancias fortuitas y controlables (aislamiento respecto del otro sexo, ambiente, timidez personal, inducción personal, etc.).

Según nuestro modo de ver, esta distinción es fundamental para formular criterios y juicios sobre el hecho de la homosexualidad, y que, de un modo sucinto, pueden esquematizarse del modo siguiente: 1) Homosexuales naturales. Tienen derecho a vivir su identidad sexual, siempre que lo hagan de un modo personalmente integrador y socialmente discreto. También es cierto que pueden reprimir su tendencia íntima para conformarse a las expectativas sociales sobre el comportamiento sexual. Las demás personas deben tolerancia y comprensión con estos homosexuales naturales; 2) Homosexuales circunstanciales. Su caso es muy distinto al anterior. No tendrían por qué ser homosexuales y, según esto, lo ideal es una terapia educativa que los vuelva al comportamiento sexual común que también para ellos tiene previsto la naturaleza. Así deben entenderlo y en este sentido han de esforzarse y los demás deberán ayudarlos. Para ellos la homosexualidad no es un derecho, sino un lamentable despiste vital.

El comportamiento sexual es algo muy serio en la vida, y lo que no puede haber en el mismo es antojo, irresponsabilidad y desorden, sobre todo teniendo en cuenta las consecuencias humanas que pueden seguirse para otros. Lo ideal es integrar el sexo en el amor, y todo ello en un plan 
de vida personal y social conforme con el verdadero bien de las personas y de la sociedad. En el sexo no sólo hay derechos, sino también deberes; deberes para con uno mismo y para con los demás. La homosexualidad irresponsable no es un derecho de las personas, sino un abuso y una desviación de la conducta. A la felicidad humana no se llega por un camino cualquiera ni por simples antojos; tiene unas exigencias, tiene unas normas y la persona sabia trata de conocerlas y conformarse a ellas.

El caso de la homosexualidad indebida es grave, pues entraña consecuencias no sólo para el interesado, sino también para pobres incautos. A veces se dice que la sexualidad es un juego; en la sexualidad hay un juego, pero ella es más que un juego, es algo bastante serio y que toca aspectos profundos de la persona. Hay derecho a la sexualidad, pero sujeto a las normas de la ética, sin las cuales el comportamiento humano cae en el mal.

Una simple inclinación homosexual no justifica la conducta homosexual, la cual sólo queda justificada cuando se trata de una inclinación tan fuerte y evidente que su frustración supondría un desequilibrio psíquico notable para el sujeto. En otros casos la Higiene Mental puede ofrecer oportunas soluciones. La sexualidad humana no es mecánicamente determinante; constituye una fuerza plástica que puede modificarse, encauzarse y hasta transformarse, de acuerdo con lo que el sujeto decida, de modo que es él quien ha de mandar en su sexualidad, y no su sexualidad quien ha de mandar en él.

En la moral católica moderna M. Vidal (1991b) distingue una postura moral "aggiornata» de otra postura rupturista. La primera representa una postura progresista pero ortodoxa, y en ella autores como B. Häring y M. Oraison distinguen dos tipos de comportamientos homosexuales: 1) unos son de "desintegración sexual» (aberraciones sexuales, promiscuidad, prostitución, actos no vinculantes), que son calificados como inmorales, según las mismas normas y criterios con que se juzgan los comportamientos heterosexuales. 2) Para los casos de "integración homosexual" hay dos tendencias: hay autores que condenan la relación homosexual completa; otros autores (Valsecchi, Curran), en cambio, aceptan y justifican los comportamientos homosexuales «estables». 
Pero la postura rupturista rompe con la tradición moral vigente y se abre a soluciones radicalmente nuevas. H. Spijker propone que el tema moral de la homosexualidad debe resolverlo subjetivamente cada persona que se encuentre afectada por ella, pues "lo personal nunca es repetible y ha de dejarse en manos del criterio de la persona" (M. Vidal 1991b, p. 277). J.J. McNeill admite que el criterio básico que determina el buen comportamiento sexual es el de la fidelidad y de la estabilidad integradora de la vida sexual, y esto vale tanto para las parejas heterosexuales como para las homosexuales, de modo que estas últimas serían legítimas.

\section{El derecho al aborto}

El caso del aborto es quizá uno de los que mejor nos permiten distinguir entre el ámbito del Derecho y el de la Ética, mostrándonos la necesidad incluso de hacerlo. Pues ocurre que el aborto constituye una práctica bastante generalizada, defendida por muchas personas y grupos; y como su oposición a la moralidad no es evidente, la sociedad se ve llevada a tolerar esa práctica, y los legisladores, por consiguiente, a regularla permisivamente por la ley. Ahora bien, queda latente la legitimidad moral del aborto, siendo una cuestión que cae más allá (o más acá) de la ley, convirtiéndose en una actitud adoptada por individuos según su conciencia, o por grupos según la ideología que les es propia.

Hay que distinguir, pues, entre un derecho legal al aborto y un derecho moral al aborto. En nuestra opinión - según presuponíamos al comienzo el derecho legal debería subordinarse al derecho moral. En consecuencia, es éste el que aquí nos interesa, y nos disponemos a hacer en torno al mismo algunas reflexiones libres que nos puedan ayudar a encauzar el asunto.

Asunto que, en su teoría, no está nada claro. La propia Iglesia católica, que de un modo tan constante y enérgico ha mantenido una posición en este punto, carece, sin embargo, de una fundamentación suficiente de la misma, sirviéndose más bien de afirmaciones e intuiciones tradicionales. Representando dicha posición escribe M. Vidal (1991c, p. 402): «Reconocemos la inmoralidad del aborto tomado globalmente y despojado 
de las sobrecargas que le pueden sobrevenir. Esta valoración se apoya en los contenidos humanos que integran la realidad del aborto».

Son bastantes los que concuerdan con este punto de vista, para el cual, como dice J. M. ${ }^{a}$ Barrio (1995, p.199), con la práctica del aborto "se acepta que el derecho de la fuerza prevalezca sobre la fuerza del derecho". Cuando quieren fundamentar su posición suelen apelar a uno de estos dos argumentos: 1) la vida en general es un valor sagrado, y por lo mismo no es lícito atentar contra ella; 2) el aborto es un homicidio.

En nuestro libro Pedagogía Moral (Quintana 1995, p. 237) incidentalmente hemos querido hacer ver la poca base de tales argumentos: el primero porque la vida no constitye un valor absoluto, sino relativo, y son muchas las formas de vida que el hombre viene destruyendo sin ningún escrúpulo moral. Lo que es un valor muy importante es la vida humana, y es sólo ésta la que hay que considerar en el caso del aborto. $\mathrm{Y}$ aun entonces puede y debe distinguirse entre "individuo" y "persona", haciendo notar que es sólo la persona sujeto de derechos. El problema está, entonces, en saber si el aborto destruye la persona humana. Que destruye un "individuo" eso es seguro, pero puede no tener relevancia moral. Lo tendrá, en cambio, si con el aborto se atenta a la vida de una "persona”. Pero ¿es acaso el embrión humano ya una persona desde el primer momento? Y si no, ¿cuándo comienza a serlo? Quien tenga la respuesta verdadera a tales preguntas tendrá también la solución a la licitud o inmoralidad del aborto (con esto queremos indicar, únicamente, que es ésta una cuestión que no ha de resolverse de un modo intuitivo, emocional o dogmático - es decir, irracional -, sino como todos los problemas de la moral, a saber, partir de unos principios correctos y sacando de ellos consecuencias por vía lógica). Y a falta de seguridad en aquellas premisas, son bastantes los que, aplicando a su modo el segundo principio que hemos aducido (la distinción entre individuo y persona), se atienen a esta regla que así expresa J. Sádaba (1997, p. 25): “el aborto será objetable traspasados ciertos límites, mientras que no se ve por qué habría que condenarlo dentro de límites biológicamente aceptables".

Quien tiene ahí razón no lo sabe nadie, ni se sabrá quizá nunca. Ese derecho o no-derecho ha de constituir, pues, en la práctica, una cuestión 
de prudencia, de sabiduría. Guardándonos de principios falsos como el siguiente, enunciado por el mencionado J. Sádaba: "antes de nacer uno no tiene derecho a nada. Sólo los sujetos de derechos - sujetos reales poseen derechos” (p. 29). Esto valdrá para los derechos jurídicos; pero los derechos morales, es decir, los derechos humanos los tiene uno ya en cuanto es persona.

\section{El derecho a disponer del término de la vida}

Vamos a distinguir aquí tres casos, que no tienen exactamente las mismas connotaciones, aun cuando tienen evidentes puntos de contacto: nos referimos al suicidio, a y a la eutanasia, sobre los cuales vamos a hacer alguna reflexión.

El suicidio. A algunos les parece que el suicidio no puede revestir mucha gravedad, dado que uno no perjudica a nadie sino sólo a sí mismo, y admitiendo que "mi cuerpo es mío y de él puedo hacer lo que quiera”... Esta óptica viene alentada por aquella concepción de la ética, tan preponderante hoy día, según la cual los preceptos morales los construyen los grupos sociales por consenso, de un modo dialógico, y no tienen otra finalidad que asegurar la práctica de la justicia, es decir, el garantizarse a todos el que sean respetados sus derechos individuales. Es la moral social, como única forma de moral, y que se atiene a aquel principio enunciado por A. Bertrand que ya hemos recordado. Con este tipo de moral constructivista, claro está, poco hay que decir sobre el suicidio, que no sería cuestión de moral.

A esta misma conclusión se llega desde la ética "de la responsabilidad", de que habla Max Scheler, y que viene a ser lo mismo: la moralidad estriba sólo en ser positivamente responsable, es decir, abstenerse de que los actos del sujeto puedan dañar a otros. No hay, pues, actos buenos o malos en sí mismos (será malo matar a otro, pero no matarse a sí propio). Ya se adivina que esta teoría viene a coincidir con la ética "consecuencialista", a la que ya hemos aludido. 
Ahora bien, el mismo Scheler explica que, junto a esa ética, hay también otra diferente, a saber, la ética "de la convicción" (o "de la decisión", que dicen muchos, traduciendo mal a Scheler: Gesinnungsethik, ética del modo de ver, de sentir), en dependencia de la idea que uno tiene de la moral, admitiendo la moralidad intrínseca de los actos mismos, aun aparte de sus consecuencias. Este último punto de vista es también el de la moral tradicional, según la cual - dice M. Vidal (1991c, p. 422) objetivamente hablando "el suicidio aparece como una opción claramente negativa al colocarlo dentro de un horizonte de preferencias humanas y humanizadoras", por varios motivos y en varios aspectos. Es más: el suicidio es moralmente incluso peor y más grave que el homicidio. Esta sorprendente afirmación se basa en el hecho de que, para un individuo, su propia vida es un bien superior a la vida ajena (y por eso existe la norma moral de que uno puede matar en defensa propia). Así pues, si el homicidio es horrible, el suicidio, en teoría, ha de serlo todavía más.

Todos sabemos que, en la mayoría de los casos, el suicidio constituye un acto poco consciente y responsable. Ahora bien, hay un caso en que el sujeto actúa conscientemente, pero hallándose asistido de motivos al parecer tan razonables y de unas circunstancias tales que suprimirían en su acto el carácter de ser moralmente negativo. Es el caso de cuando el sujeto se ve, por ejemplo, acosado de una enfermedad terminal y, creyendo más ventajoso adelantar el momento de su muerte, decide hacerlo. Es la ortotanasia, que ahora vamos a comentar.

La ortotanasia consiste en la decisión que el sujeto mismo toma con respecto a las circunstancias que desea, como mejores, para su propia muerte natural, en cuyo proceso, de algún modo, ya ha entrado. Estas peculiaridades distinguen la ortotanasia (o "muerte correcta") del suicidio, en el cual la muerte es totalmente artificial y biológicamente descontextualizada.

La ortotanasia, defendida por varios, y relacionada en cierto modo con la eutanasia, con la cual la unen consideraciones comunes, y no exentas de buen sentido, constituye un actual objeto de debate. Defienden la ortotanasia personas razonables, como S, Paniker, el cual incluso ha fundado 
una asociación para explicar y difundir esas ideas. Pero nosotros vamos a exponer aquí la teoría de J. Rubio, el cual, en su libro Ética constructiva $y$ autonomía personal (1992), habla del derecho de la persona a una "autonomía para morir", que él llama "autonomotanasia”, basada en la libre disposición del individuo sobre las condiciones y circunstancias de la propia muerte. Aduce, en defensa de este derecho "inalienable", precedentes en la historia humana cultural, como los hay en la antigua Roma.

Se trata del "derecho humano a elegir la propia muerte de forma responsable y solidaria" (p. 297), derecho que ha de ser reivindicado - dice - frente a los tabúes vehiculados por la religión, a las leyes del Estado y a la resistencia de los médicos a colaborar en esos actos (y colaborando, en cambio, en prolongar la vida a veces en unas circunstancias tan onerosas como desesperadas: es la "distanasia"). Se trata - dice - de superar o diseñar una nueva cultura de la muerte, por la cual la persona madura y consciente decide sobre el fin de su vida, de un modo personalmente responsable (en congruencia con el proyecto de vida que ha ido desarrollando) y teniendo la debida solidaridad con los demás y coherencia con las propias creencias y sentido de la vida. "O que, al menos - ya que estamos hablando de mínimos -, no contradiga o sea disonante con su trayectoria axiológica global" (p. 305). J. Rubio entiende que "la autonomía moral para morir, como continuación y culminación de la autonomía moral para vivir", es un "derecho humano fundamental" (p. 307).

Podríamos hacer aquí algunas reflexiones, que también valdrán para el caso de la eutanasia. Desde instancias religiosas se recuerda, razonablemente, que el hombre no es dueño de su vida, sino solo un depositario de la misma, de modo que carece de un derecho absoluto sobre ella. La vida sería un medio que se le proporciona para que así pueda realizar unos valores superiores, que serían el fin de su vida, de la cual no podrá disponer, pues, como le plazca. Esta misma concepción puede defenderse también desde un simple humanismo. En todo caso parece claro que la vida constituye un valor humano superior a otros como pueden ser el bienestar, el goce y hasta la propia felicidad, de tal manera que constituiría una inversión de valores (es decir, un acto inmoral) el posponer la vida a esos valores. 
La eutanasia. Con respecto a lo anterior también suele decirse que la vida es un bien superior a la "calidad de vida", y este principio es el que haría inmoral tanto la eutanasia como la ortotanasia, las cuales quieren fundarse precisamente en una prioridad de la calidad de vida como valor, cosa que parece muy cuestionable.

Los contrarios a la eutanasia suelen invocar, aparte motivos religiosos, el de que la muerte constituye un proceso natural, y no es lícito torcer el curso de la naturaleza en asuntos tan graves, erigiéndose uno en señor de la vida y de la muerte (y de la de los demás). Los otros argumentarán que la naturaleza no siempre actúa bien, y precisamente ahí está la razón humana para corregir la naturaleza y, así, conseguir algo mejor. Dice M. Vidal (1991c, p.507) que la cuestión es compleja porque se trata de respetar y conjugar no un solo valor, sino estos dos: $1 .^{\circ}$ el respeto a la vida humana, y $2 .^{\circ}$ el derecho a morir dignamente. La eutanasia no realiza el primero, y la distanasia (o prolongación artificial y exagerada de la vida usando adelantos médicos) no realiza el segundo; lo que realiza ambos es la "ortotanasia" (pero tomada no en el sentido que antes hemos visto, sino en el que acabamos de decir).

A menudo se presenta la eutanasia como una forma de humanismo y, bien entendida, puede muy bien serlo. El peligro está en que se deshumanice, por los abusos a que muy fácilmente puede dar lugar. Aparte de que conviene profesar una doctrina antropológica de valoración del dolor, como elevador del alma y purificador de la misma, que debe ser muy tenida en cuenta, aun en un plano simplemente humanista. La evitación de todo dolor y de toda molestia, tanto por parte del propio paciente como de quienes lo cuidan, se sale de los esquemas de una vida íntegra y digna. No se trata de ser mártir ni de hacer mártires, pero tampoco de rehuir cobarde o egoístamente la prueba del dolor, que acrisola las almas.

El otro punto de vista, el que defiende la eutanasia y el derecho a decidir sobre la propia muerte, descansa sobre un concepto de libertad omnímoda, en que el sujeto humano decide más allá de la naturaleza y de los valores. Por eso J.M. ${ }^{a}$ Barrio (1996, p. 275) dice que "este concepto prometeico de libertad humana responde a las exigencias de un discurso más retórico que teórico", pues "un pleno dominio sobre sí, excluyente 
de cualquier cortapisa, es una ilusión de libertad", que desconoce el sufrimiento, el cual, si bien puede destruir al hombre, puede también enriquecerle profundamente, pues "sufrir es elevar un acontecimiento meramente biológico a una categoría moral superior" (p. 277).

\section{Conclusión}

Hemos pretendido llamar la atención sobre la complejidad teórica de las cuestiones morales humanas y reflexionar sobre ciertos derechos humanos con la intención de promover el rigor en su conceptualización. Aparte de discutir la noción del derecho, nuestro análisis se ha enfocado, particularmente, en los derechos del poder equivocar-se, de la huelga, de la desobediencia civil y la objeción de conciencia, de disponer del propio cuerpo, el de la opción sexual, así como el derecho al aborto y el de poder poner fin a la vida personal. No aspiramos a dar aquí soluciones finales, sino a profundizar en el estudio crítico de los temas.

\section{Bibliografía}

Barrio, J. M. (1995). La ética de la decisión, o la vuelta de Prometeo: Notas para una reflexión bioética. Cuadernos de Bioética, ${ }^{\circ}{ }^{\circ}$ 2, pp. 196-203.

Barrio, J. M. (1996). La eutanasia. Una reflexión antropológica. Cuadernos de Bioética, n. ${ }^{\circ}$ 3, pp. 275-80.

Bonilla y San Martín, A. (1897). Concepto y teoría del derecho. Madrid: Librería de Victoriano Suárez.

Canto-Serber, M. (Dir.). (1996). Dictionnaire d'éthique et de philosophie morale. Paris: P.U.F. Descartes, R. (1983). Discurso del método. Reglas para la dirección de la mente. Barcelona: Orbis. Jolivet, R. (1959). Tratado de Filosofía Moral. Buenos Aires: Carlos Lohlé.

Popper, K. R. (1967). El desarrollo del conocimiento científico. Conjeturas y refutaciones. Buenos Aires: Paidós.

Quintana Cabanas, J.M. (1984). Pedagogía Social. Madrid: Dykinson.

Quintana Cabanas, J.M. (1989). Sociología de la Educación. Madrid: Dykinson.

Quintana Cabanas, J.M. (1995). Pedagogía Moral. El Desarrollo Humano Integral. Madrid: Dykinson

Quintana Cabanas, J.M. (1998). Pedagogía Axiológica. La educación ante los valores. Madrid: Dykinson 
Rawls, J. (1995, 2. ${ }^{a}$ Ed.). Teoría de la Justicia. México: Fondo de Cultura Económica. Rubio Caracedo, J. (1992). Ética constructiva y autonomía personal. Madrid: Tecnos. Sádaba, J. (1997). Diccionario de Ética. Barcelona: Planeta.

Tomás de Aquino, Santo (1959). Suma Teológica. Madrid: B.A.C., Tomo III (2. ${ }^{\circ}$ ).

Vidal, M. (1991a): Moral social. Madrid: PS Editorial.

Vidal, M. (1991b): Moral del amor y de la sexualidad. Madrid: PS Editorial.

Vidal, M. (1991c): Moral de la persona y Bioética teológica. Madrid: PS Editorial. 